he also reviews the present programmes for the improvement of positions and proper motions to the ninth magnitude.

Part 4, "Geometric Methods", includes papers on Project $A N N A$ by Macomber and on the transit system by Guier. Hirose describes a simple method of triangulation using one timing camera and two equatorially mounted cameras without any special timing devices, at the three apices of a triangle. Gordon describes equipment and methods for determining geodetic positions by satellitestar occultations.

In Part 5, "Numerical Results", Kozai, King-Hele, Michielsen, Newton and Izsak give up-to-date values of the coefficients of zonal harmonics of the Earth's gravitational field as far as $J_{8}$ and $J_{9}$, also some tesseral harmonies. $J_{5}$ to $J_{9}$ appear to be of order $0.1 \times 10^{-6}$, but, as is pointed out, as soon as higher $J_{n}$ 's are determined, all the previously accepted values of the lower $J_{n}$ must be revised; and there still appears to be doubt about terms involving $\left(J_{2}\right)^{2}$ which will affect estimates of $J_{4}$ and higher terms of the same order as $\left(J_{2}\right)^{2}$.

Part 6, "Comparison with Other Methods", compares and combines satellite observations with gravity data. Kaula and Mrs. Fischer compare geoid heights based on satellite data with those determined astro-geodetically. Kaula states that the locations of the major continental geodetic systems of the world have been shown to be probably correct to 100 metres, but that the scale relationship of the satellite system to the c.G.s. system is inconclusively determined at the moment. Rabe also compares the values of $G M$ obtained by terrestrial and astronomical methods. Uotila gives the coefficients of low-degree spherical harmonies of the gravity field as computed from surface gravity anomalies, while Molodensky, Yeremeyev and Yourkina evaluate the accuracy of Stokes's theorem and attempt to improve his theory. It is pleasing to note that the old controversy (if that is not too strong a word) about the triaxial spheroid now seems to be dying a natural death, and several authors plead in effect with Mrs. Fischer: "It is suggested not to use triaxiality with its geophysical connotation as a figure of speech for $J_{22}$, but to call a coefficient a coefficient".

Part 7, "Geophysical Implications", consists of a paper by MacDonald entitled "Geophysical Implications of Satellite Geodesy", and "The Effects of Convection in the Mantle on the Gravitational Field of the Earth", by Kopal. Finally, Part 8 is a "Closing Summary of the Symposium", by A. H. Cook.

In a short review such as this it is impossible to mention all the papers, but it is hoped that enough has been said to illustrate the scope and quality of this book. In addition it is extremely well produced and almost without misprints, for which the editor and publishers are to be congratulated. It well deserves a place in the library of all who wish to use artificial satellites in order to obtain information about position or the Earth's gravity field.

A. R. RobBins

\section{ROCK PRESSURES IN OIL AND GAS DEPOSITS}

Initial Rock Pressures in Oil and Gas Deposits

By B. A. Tkhostov. Translated by R. A. Ledward. Pp. viii +118 . (London and New York: Pergamon Press, 1963.) 50s. net.

THE motive force in an untapped oil or gas reservoir is the latent energy due to environmental rock pressure. Unlike solid mineral resources, the fundamentally distinguishing feature of oil pools is the presence therein of sufficient natural energy, once released, for the partial, if not complete, extraction of their contents. In a majority of oil and gas deposits initial rock pressure corresponds to the hydrostatic pressure of the geological environment concerned or at least differs little from it. But there are exceptions, often described as 'anomalous', when there is a large excess of initial rock pressure over local hydrostatic pressure, which in this context is defined as "the pressure of a column of water whose height is equal to the depth of occurrence of the bed". This assumption implies a common level for the outerop of the bed and the collar of the well from which the pressure is determined. B. A. Tkhostov's thesis is that causes of anomalously high pressures are similar to those of normal rock pressures, and that in the former case values differ because geological conditions controlling development of rock pressures are different.

Initial Rock Pressures in Oil and Gas Deposits aims at elucidation of the causes determining rock pressure, also of those cases where anomalous high values obtain. The survey covers factual data relating to initial rock pressures recorded from oilfields in the Urals-Volga area, the Caucasus, the Ukraine, Central Asia, the United States and Canada. Apart from the author's own interpretations of the problem, the opinions of other research workers concerned are critically analysed. The result is a very readable exposition of the controliing factors of oil and gas production, especially in the initial stages of development of new fields, which have hitherto tended to be somewhat parochial in individual records, lacking a common denominator of philosophical explanation.

The treatment of the subject includes a review of research into the problem in the countries mentioned; consideration of conditions determining the state and magnitude of rock pressures in oil and gas deposits; distribution of deposits according to tectonic zones and ages (the major part of the book, wherein Devonian and Carboniferous, Mesozoic and Tertiary formations are separately described), and a discussion of particular oil and gas deposits where anomalously high initial rock pressures have been recorded. The volume concludes with four appendixes tabulating initial rock pressures and other data from a large number of locations in the U.S.S.R. There are fifty-four references to authors quoted in the text, mostly Russian.

The translator, R. A. Ledward, has done his work well and the English reader is presented with an easily understandable conception of the author's motive in publishing this book.

H. B. MHLNer

\section{PHYSICAL GEOCHEMISTRY}

\section{Physical Geochemistry}

By F. Gordon Smith. (Addison-Wesley Series in Earth Science.) Pp. $x+624$. (Reading, Massachusetts, Palo Alto and London: Addison-Wesley Publishing Company, Inc., 1963.) $113 s$.

IN the application of physico-chemical theory and hightemperature, high-pressure experimental results to petrology and to economic geology, as in any rapidly expanding field, comprehensive reviews and text-books are lacking. Physical Geochemistry is designed to remedy the present deficiency. The scope and purpose of the book are expressed by the author: "The subject matter is divided into two parts: the first is a systemization of theoretical aspects of crystals, and of systems including crystals, especially minerals, and the second is a synthesis of a self-consistent theory of high-temperature, highpressure processes which are related to igneous rocks and mineral deposits. The first part could form the subject matter of an undergraduate course in geology for supplementing prior instruction in physical and inorganic chemistry, and the second part could form the basis of a graduate lecture course or seminar in petrogenesis".

of the first, undergraduate part, approximately half is devoted to a compressed account of crystal chemistry 